\title{
Fatigue Crack Propagation Behavior of RC Beams Strengthened with CFRP under High Temperature and High Humidity Environment
}

\author{
Dongyang Li, ${ }^{1}$ Peiyan Huang, ${ }^{1,2}$ Guang Qin,, Xiaohong Zheng, ${ }^{1}$ and Xinyan Guo ${ }^{1}$ \\ ${ }^{1}$ School of Civil Engineering and Transportation, South China University of Technology, Guangzhou 510640, China \\ ${ }^{2}$ State Key Laboratory of Building Science, South China University of Technology, Guangzhou 510640, China \\ Correspondence should be addressed to Peiyan Huang; pyhuang@scut.edu.cn
}

Received 13 September 2016; Accepted 21 December 2016; Published 15 January 2017

Academic Editor: Giuseppina Amato

Copyright ( 92017 Dongyang Li et al. This is an open access article distributed under the Creative Commons Attribution License, which permits unrestricted use, distribution, and reproduction in any medium, provided the original work is properly cited.

Numerical and experimental methods were applied to investigate fatigue crack propagation behavior of reinforced concrete (RC) beams strengthened with a new type carbon fiber reinforced polymer (CFRP) named as carbon fiber laminate (CFL) subjected to hot-wet environment. $J$-integral of a central crack in the strengthened beam under three-point bending load was calculated by ABAQUS. In finite element model, simulation of CFL-concrete interface was based on the bilinear cohesive zone model under hotwet environment and indoor atmosphere. And, then, fatigue crack propagation tests were carried out under high temperature and high humidity $\left(50^{\circ} \mathrm{C}, 95 \% \mathrm{R} \cdot \mathrm{H}\right)$ environment pretreatment and indoor atmosphere $\left(23^{\circ} \mathrm{C}, 78 \% \mathrm{R} \cdot \mathrm{H}\right)$ to obtain $a$ - $N$ curves and crack propagation rate, $d a / d N$, of the strengthened beams. Paris-Erdogan formula was developed based on the numerical analysis and environmental fatigue tests.

\section{Introduction}

External bonding of carbon fiber reinforced polymer (CFRP) composites has become more and more widely used for strengthening RC structures all over the world in the past two decades $[1,2]$ due to its lightweight, high strength, and good erosion resistance. Many researchers have demonstrated that external bonding of CFRP can obviously improve the fatigue performance of RC structures [3-5]. In subtropical regions, hot-wet environment has a marked effect on fatigue performance and durability of the RC bridge components strengthened with CFRP and even leads to the components being not able to meet the safety, reliability, and durability requirements in the whole life cycle [6]. Therefore, study on fatigue crack propagation behavior of RC structures strengthened with CFRP in hot-wet environment has important scientific significance. However, the effect mechanism of hotwet environment on the fatigue crack propagation behavior of strengthened RC structures remains unclear.

Previous studies of our research group $[7,8]$ show that Paris-Erdogan law [9] was an effective method to study fatigue crack propagation behavior in RC structures strengthened with CFRP. However, considering the quasi-brittle and nonlinear characteristic of concrete, stress intensity factor (SIF) has limitations to explain crack initiation and propagation in concrete [10]. $J$-integral is more sufficient to describe the crack propagation behavior in concrete [11]. According to the $J$-integral approach, the fatigue crack propagation rate, $d a / d N$, is put in relation to the cyclic $J$-integral amplitude, $\Delta J$.

In the calculation of $J$-integral, concrete damage plastic (CDP) model uses concepts of isotropic damage in combination with tensile and compressive plasticity to represent the nonlinear-elastic behavior of concrete. Also, concrete materials show different response under fatigue load compared with static load. Petryna et al. [12] developed a fatigue damage model of reinforced concrete, which was capable of simulating arbitrary damage states under cyclic loading. Sain and Chandra Kishen [13] and Zanuy et al. [14] illustrated tensile and compressive behavior of concrete under fatigue loading, respectively. J.-S. Zhu and X.-C. Zhu [15] proposed a numerical simulation method of the full-range fatigue 

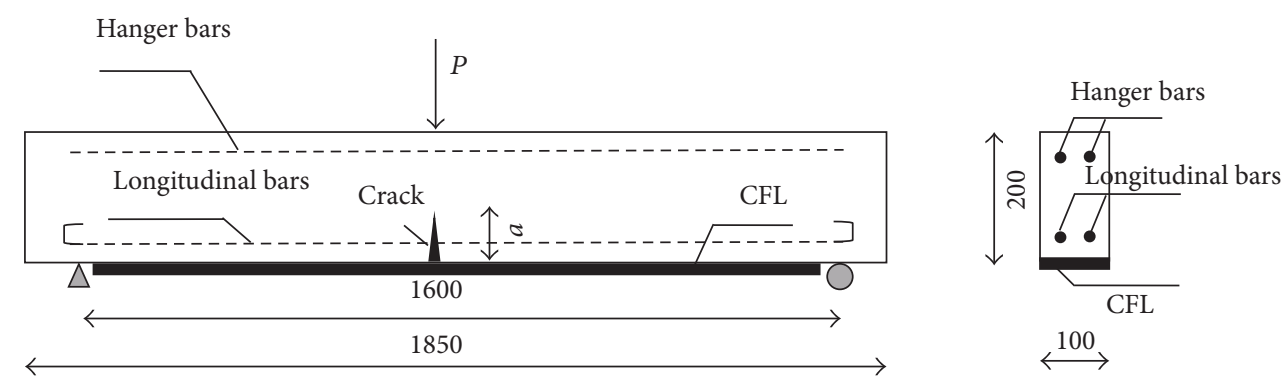

FIGURE 1: CFL-strengthened RC beam with a crack (unit: mm).

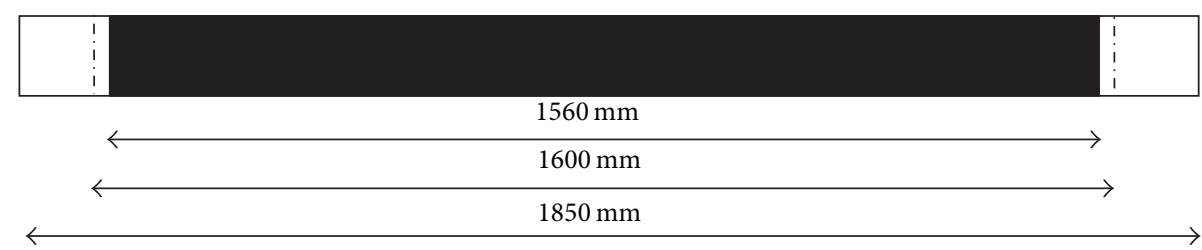

FIGURE 2: Size of CFL pasted at the bottom of RC beam.

damage accumulation failure of RC bridges, based on the CDP model in ABAQUS [16].

As many studies [16, 17] show, interface debonding is the main failure mode of the RC beams strengthened with FRP under static and cyclic loading. Moreover, hot-wet environment has a significant influence on bonding behavior of the CFRP-concrete interface [6, 18]. Qin et al. [19] found that hot-wet environment has a harsh influence on fatigue durability of RC structure strengthened with FRP. Therefore, the constitutive relation of the CFRP-concrete interface under hot-wet environment would be applied to discuss the fatigue crack propagation behavior. Zheng et al. [6, 18] investigated the behavior of FRP-concrete interface under hotwet environment through double-shear tests, which provided significantly guidance for the simulation of FRP-concrete interface in detail later in this paper.

Against the above background, the present paper is divided into two main sections. Firstly, a finite element model of RC beam strengthened with CFRP was established for determination of $J$-integral of main crack based on nonlinear fracture mechanics, considering CFRP-concrete interface behavior under different environment. Secondly, several fatigue crack propagation tests were carried out for RC beams strengthened with CFL under high temperature and high humidity $\left(50^{\circ} \mathrm{C}, 95 \% \mathrm{R} \cdot \mathrm{H}\right)$ and indoor atmosphere $\left(23^{\circ} \mathrm{C}\right.$, $78 \% \mathrm{R} \cdot \mathrm{H}$ ) to obtain fatigue crack propagation rate, $d a / d N$. Then, Paris law with $J$-integral was developed to describe the fatigue crack propagation behavior, which can be applied to predict the fatigue lives of the RC beams strengthened with CFRP.

\section{FEM for Calculation of $J$-Integral}

A finite element model of CFL-strengthened RC beam was built to calculate $J$-integral using the commercial finite element (FE) software ABAQUS in this paper. Geometry, material properties, and mesh division of the strengthened beam were introduced in detail later. Moreover, nonlinear and fatigue behavior of concrete and effect of hot-wet environment were considered.

2.1. Geometry of Specimen. Three-dimensional FE model of the simply supported RC beam strengthened with carbon fiber laminate (CFL) [20] was shown in Figure 1. CFLstrengthened RC beam was subjected to three-point bending (3PB) load with a crack at midspan. The size of RC beam was $1850 \mathrm{~mm}$ length $\times 100 \mathrm{~mm}$ width $\times 200 \mathrm{~mm}$ height. Distance between the supports was $1600 \mathrm{~mm}$ and height of crack was $a$. The internal steel bar consisted of two $\varphi 10 \mathrm{~mm}$ longitudinal bars and two $\varphi 8 \mathrm{~mm}$ hanger bars. CFL with a cross section of $100 \mathrm{~mm}$ (width) $\times 0.23 \mathrm{~mm}$ (computing thickness) and a total length of $1560 \mathrm{~mm}$ was bonded to the bottom of RC beams (Figure 2).

\subsection{Material Properties and Constitutive Models}

(1) Nonlinear Behavior of Concrete. The compressive and tensile behaviors of concrete with nonlinear properties were described by the stress-strain curve (provided by the standard GB50010-2010 [21]) as shown in Figure 3. The stress-strain curve of the concrete was described as

$$
\sigma=\left(1-d_{c}\right) E_{c} \varepsilon
$$

where $E_{c}$ is the initial elastic modulus. For the compressive behavior, $d_{c}=1-\rho_{c} /\left[\alpha_{c}(x-1)^{2}+x\right], \rho_{c}=f_{c} / E_{c} \varepsilon_{c}, n=$ $E_{c} \varepsilon_{c} /\left(E_{c} \varepsilon_{c}-f_{c}\right), x=\varepsilon / \varepsilon_{c}$, and $\alpha_{c}=0.74 \sim 3.99$ (when $f_{c}=$ $20 \sim 80 \mathrm{MPa}$ ); $f_{c}$ is the uniaxial compressive strength; $\varepsilon_{c}$ is the strain values when $\sigma$ reaches $f_{c} ; d_{c}$ is the damage evolution parameter of concrete under uniaxial compression loading. For the tensile behavior, $d_{c}=1-\rho_{t} /\left[\alpha_{t}(x-1)^{1.7}+x\right], \rho_{t}=$ $f_{t} / E_{c} \varepsilon_{t}, x=\varepsilon / \varepsilon_{t}, \alpha_{t}=0.31 \sim 5$ (when $f_{t}=1 \sim 4 \mathrm{MPa}$ ); $f_{t}$ is uniaxial tensile strength; $\varepsilon_{t}$ are strain values when $\sigma$ reaches $f_{t}$. 


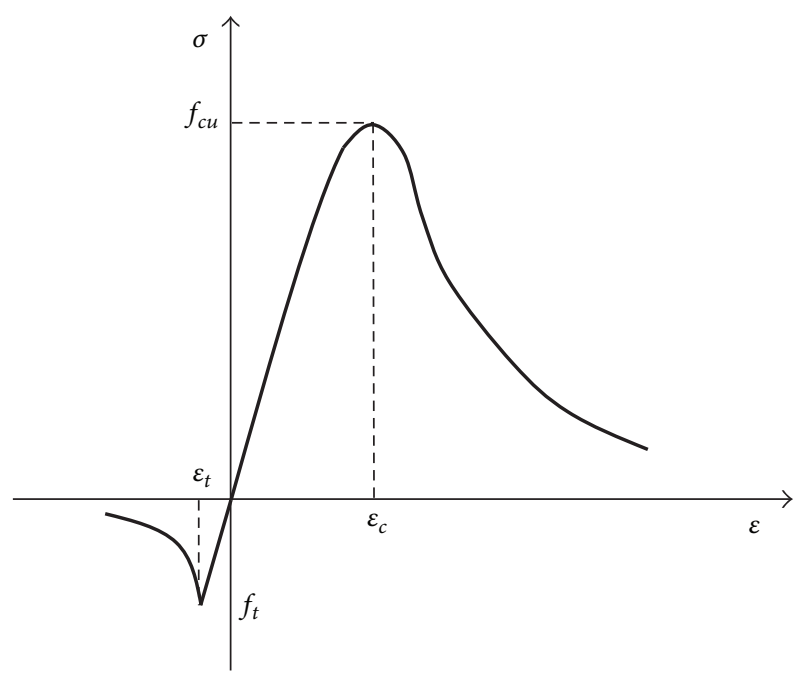

FIGURE 3: Uniaxial stress-strain curve of concrete.

The constitutive model, which is called concrete damage plasticity (CDP) model, was used for the numerical calculations in ABAQUS. CDP model was implemented for modeling tensile cracking and compressive crushing behavior of concrete, which was shown in Figure 3.

The elastic modulus, Poisson's ratio, tensile strength, and compressive strength of the concrete were $E_{c}=35.2 \mathrm{GPa}, \nu_{c}=$ $0.193, f_{t}=4.45 \mathrm{MPa}, f_{c}=37.3 \mathrm{MPa}$, and $\varepsilon_{c}=0.00175, \varepsilon_{t}=$ 0.000095 .

(2) Elastic Modulus Degradation of Concrete. Steel bar in RC beams strengthened with CFRP remains linear-elastic before yielding in fatigue test. Also, due to excellent fatigue resistance, CFRP keep linear-elastic in most of fatigue life [22]. Thus, this paper placed emphasis on fatigue damage evolution of concrete instead of steel bar and CFRP, including consideration of the effective elastic modulus and residual strength of concrete.

Based on test results, Holmen [23] proposed a formula about effective elastic modulus of concrete under fatigue loading:

$$
E_{N}=\left(1-0.33 \frac{N}{N_{f}}\right) E_{c}
$$

where $E_{N}$ is the effective elastic modulus of concrete at $N$ loading cycles; $E_{c}$ is initial elastic modulus of concrete; $N_{f}$ is the number of loading cycles to failure (fatigue life).

(3) Strength Degradation of Concrete. Many researchers [14] applied envelope concept to describe the degradation process of concrete strength. Fatigue residual strength envelope was defined as the relation curve between residual strength and loading cycles. Through the analysis of hysteretic stress-strain curves of concrete under fatigue loading, J.-S. Zhu and X.-C. Zhu [15] found that the shape of residual strength envelope was similar to the descending branch of uniaxial stress-strain curve (Figure 3 ) and established residual compressive and tensile strength envelope (shown in Figure 4).

Fatigue residual strength envelope equations based on Figure 4 and the descending branch of (1) can be given as follows:

$$
f_{i=c, t}(N)=f_{i=c, t} \cdot \frac{\left(\log N / \log N_{f}\right)\left[x\left(N_{f}\right)-x(1)\right]}{\alpha_{i=c, t}\left[\left(\log N / \log N_{f}\right)\left[x\left(N_{f}\right)-x(1)\right]-x(1)\right]^{n}+\left(\log N / \log N_{f}\right)\left[x\left(N_{f}\right)-x(1)\right]},
$$

where relative life ratio is defined as $r(N)=[x(N)-$ $x(1)] /\left[x\left(N_{f}\right)-x(1)\right]=\log N / \log N_{f}$. Therefore, $x(1)=1$, $x\left(N_{f}\right)=\log N / \log N_{f}\left[x\left(N_{f}\right)-1\right]+1 ; \alpha_{c}$ and $\alpha_{t}$ are the same as (1); $n=2$ when $i=c$, and $n=1.7$ when $i=t$.

As shown in Figures 3 and 4, compressive and tensile constitutive model of concrete under fatigue loading shared the same shape of the stress-strain curve under static loading. Therefore, fatigue constitutive model of concrete at any loading cycle $N$ was obtained through replacing the initial elastic modulus $E_{c}$, the uniaxial compressive strength $f_{c}$, and tensile strength $f_{t}$ in (1) with effective elastic modulus $E_{N}$, residual compressive strength $f_{c}(N)$, and residual tensile strength $f_{t}(N)$.

(4) Steel Bar. The steel bar was assumed to be an elasticperfectly plastic material. The elastic modulus $E_{s}=206 \mathrm{GPa}$, Poisson's ratio $v_{s}=0.3$, and yield stress $f_{y}=307 \mathrm{MPa}$. The bond between steel bar and concrete was assumed as a perfect bond, which was simulated by embedded constraint in ABAQUS.

(5) CFL. CFL is a linear-elastic composite material. Though it is obvious that CFL is orthotropic, primarily stress is in the fiber direction under three points bending load which makes the isotropic assumption suitable [24, 25]. The elastic modulus $E_{f}=230 \mathrm{GPa}$; Poisson's ratio $v_{f}=0.25$.

(6) CFL-Concrete Interface. Cohesive zone model (CZM) [26] was applied to model CFL-concrete interface. The CZM method was commonly used to simulate bond-slip relationship between CFRP and concrete. There were several shapes of bond-slip curve such as bilinear, linear-parabolic, exponential, and trapezoidal. Obaidat et al. [24] investigated the influence of the shape of bond-slip curve, and they concluded that the shape of curve had a minor effect. Alfano [27] found that bilinear law represented the best compromise between computational cost and approximation. Therefore, 


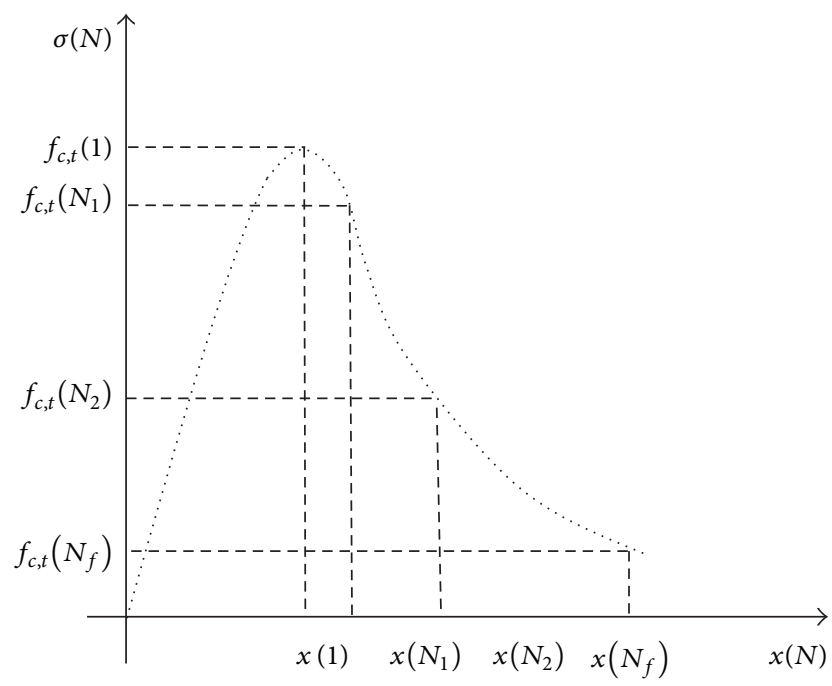

FIGURE 4: Residual strength envelope of concrete under cyclic loading.

bilinear bond-slip law was applied in this paper, which was shown in Figure 5.

Surface-based cohesive behavior in ABAQUS 6.14, which was defined as a surface interaction property based on CZM, was used to model the bond-slip behavior of CFL-concrete interface. The bilinear constitutive relation of the cohesive behavior includes the following parameters: peak value of the shear stress $\tau_{\max }$, peak value of slip $\delta_{0}$, and initial elastic stiffness $\mathrm{EI}=\tau_{\max } / \delta_{0}$. The damage initiation was determined by the slip value $\delta_{0}$ when the shear stress $\tau$ reached the peak value, $\tau_{\max }$. The linear damage evolution was described by a damage variable, $D$, which was defined by the following expression:

$$
D=\frac{\delta_{f}\left(\delta-\delta_{0}\right)}{\delta\left(\delta_{f}-\delta_{0}\right)},
$$

where $\delta_{f}=2 G_{f} / \tau_{\max }$ and $G_{f}$ is the critical fracture energy required to cause failure. $\delta$ refers to the value of slip attained during the loading history.

In the computation, different CZM parameters were used to model the bond-slip behavior of CFL-concrete interface under high temperature and high humidity $\left(50^{\circ} \mathrm{C}, 95 \% \mathrm{R}\right.$. $\mathrm{H})$ and indoor atmosphere $\left(23^{\circ} \mathrm{C}, 78 \% \mathrm{R} \cdot \mathrm{H}\right)$ environment. The parameters are based on the experimental research on bond-slip behavior of CFL-concrete interface proposed by this research group $[6,18]$, including $\tau_{\max }, \delta_{0}, \delta_{f}$, and $G_{f}$ listed in Table 1 .

2.3. Finite Element Mesh and Computing Procedure. To model the crack at midspan of CFL-strengthened RC beam, a seam was assigned through crack module as shown in Figure 6. Three-dimensional, 4-node quadrilateral shell elements (S4) were used for the CFL. Two-dimensional, 3-node truss elements (T3D2) were used for the steel bars. Threedimensional, 8-node, fully integrated hexahedral elements (C3D8) and 6-node, wedge elements (C3D6) were used for

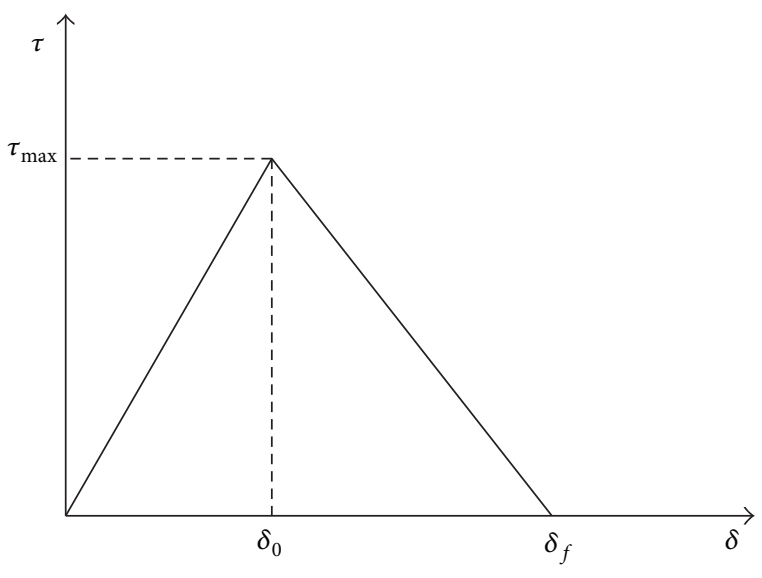

FIGURE 5: Bilinear bond-slip law.

the concrete. C3D6 elements were assigned at crack tip and C3D8 elements were assigned in other parts of concrete. Region around the crack tip was modeled using multiple rings of elements in a swept mesh which uses C3D8 elements, while C3D6 elements were assigned in the innermost rings as shown in Figure 8. Each ring provided an evaluation of the contour integral. The $J$-integral was calculated using a domain integral method [28].

To calculate $J$-integral amplitude $\Delta J=J_{\max }-J_{\min }$ $\left(J_{\max }\right.$ and $J_{\min }$ are $J$-integral under maximum stress $S_{\max }$ and minimum stress $S_{\min }$, resp.) of main crack at a certain cycle of fatigue life, the whole fatigue process was divided into multiple steps under static loading. In order to model the load process at target cycle $N$, the finite element analysis jumped over $N-1$ cycles before $N$. Fatigue degradation of the strength and elastic modulus caused by $N-1$ loading cycles were considered in the constitutive model of concrete. Two analysis steps under static load were established: (1) step (1), to calculate $J_{\min }$, load added from 0 to $S_{\min }$, in which fatigue constitutive model of concrete was considered; (2) step (2), to calculate $J_{\max }$, load added from $S_{\min }$ to $S_{\max }$ following fatigue loading curve. Thus, $J$-integral amplitude $\Delta J=J_{\max }-J_{\min }$ at a certain cycle $N$ was obtained. Complicated simulation of fullrange fatigue process was simplified as multiple steps under static loading, which gave a simple and effective method to extract $J$-integral of the RC beam strengthened with $\mathrm{CFL}$ under fatigue loading.

\subsection{Calculation and Analysis of J-Integral}

(1) Effect of Fatigue Performance Degradation of Concrete. The FE model of RC beam strengthened with CFL based on above FE analysis procedure was applied to study the effect of fatigue performance degradation of concrete on $J$-integral. Figure 7 shows $J-a / h$ curves under different relative fatigue lives $\left(N / N_{f}=0,0.2,0.4,0.6,0.8\right)$ when load level $P=$ $27.5 \mathrm{kN}$, where $N / N_{f}=0$ means no fatigue degradation of concrete was considered. As shown in Figure 7, J-a/h curves exhibit a three-stage tendency: (1) rapid increase stage: When relative crack height $a / h \leq 0.15$, the value of $J$ integral increases rapidly and almost linearly as crack height 


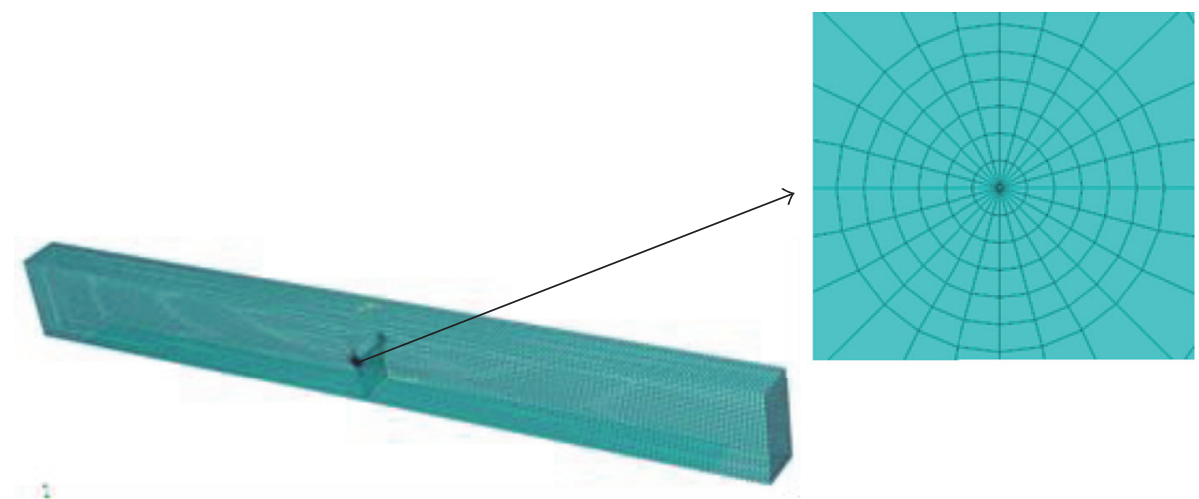

FIgURE 6: Finite element mesh of CFL-RC beam.

TABLE 1: CZM parameters.

\begin{tabular}{lccccc}
\hline \multicolumn{2}{c}{ Environment } & \multicolumn{3}{c}{ Parameters } \\
Temperature $\left({ }^{\circ} \mathrm{C}\right)$ & Humidity $(\% \mathrm{R} \cdot \mathrm{H})$ & $\tau_{\max }(\mathrm{MPa})$ & $\delta_{0}(\mathrm{~mm})$ & $\delta_{f}(\mathrm{~mm})$ & 0.068 \\
\hline 50 & 95 & 3.0 & 0.03 & 0.194 & 103 \\
23 & 78 & 6.0 & 0.06 & 583 \\
\hline
\end{tabular}



FIGURE 7: Effect of fatigue performance degradation on $J$-integral.

increases, and the value of $J$-integral reaches the highest point at $a / h=0.15$; (2) rapid decrease stage: when relative crack height $0.15 \leq a / h \leq 0.25$, the value of $J$-integral decreases rapidly and almost linearly, and an inflection point appears at $a / h=0.25$; (3) slow decrease stage: when relative crack height $a / h>0.25$, the value of $J$-integral begins to decrease slowly and nonlinearly. When relative crack height $a / h>0.7$, the value of $J$-integral tends to be zero. The three-stage tendency coincides with our previous research [7] and achieves good agreements with fatigue crack propagation behavior observed from fatigue test in chapter 3.

It can be seen from Figure 7 that the value of $J$ integral considering fatigue performance degradation is always higher than the one without consideration of degradation $\left(N / N_{f}=0\right)$. Also, at the same crack length, the value of $J$-integral increases with the increase of fatigue life. When $N / N_{f}=0.8$, the value of $J$-integral is $70 \%$ higher than the one without consideration of degradation $\left(N / N_{f}=0\right)$. It indicates that as fatigue life increases, the cracking resistance of concrete around the crack tip is significantly weakened.

(2) Effect of Hot-Wet Environment. In order to study the effect of hot-wet environment on $J$-integral, two kinds of FE model were established considering bond-slip relation under hot-wet environment and indoor atmosphere, respectively. Bond-slip parameters of CFL-concrete interface were shown in Table 1. For simplicity, fatigue performance degradation of concrete was not considered in this section. When load level $P=27.5 \mathrm{kN}, J-a / h$ curves were obtained and shown in Figure 8. As shown in Figure 8, the $J-a / h$ curves were divided into two zones. In zone $1(a / h \leq 0.45)$, the values of $J$-integral are the same whether under hot-wet environment or indoor atmosphere, because damage did not appear in the interface when $a / h \leq 0.45$ and the initial stiffness values of interface $T=\tau_{\max } / \delta_{0}$ are the same under both environments (seen in Table 1$)$. In zone $2(a / h>0.45)$, the value of $J$-integral under hot-wet environment is higher than that under indoor atmosphere, because damage appeared earlier under hot-wet environment (smaller fracture energy, seen in Table 1) than that under indoor atmosphere. Debonding was firstly found at midspan when $a / h=0.45$ under hot-wet environment. It can be concluded that hot-wet environment leads to the degradation of CFRP-concrete interface. It made cracking resistance of concrete around the crack tip weakened, which resulted in increase of $J$-integral under hot-wet environment.

\section{Fatigue Crack Propagation Tests}

A series of fatigue crack propagation tests were carried out for the RC beams strengthened with CFL under high temperatures and high humidity $\left(50^{\circ} \mathrm{C}, 95 \% \mathrm{R} \cdot \mathrm{H}\right)$ and 


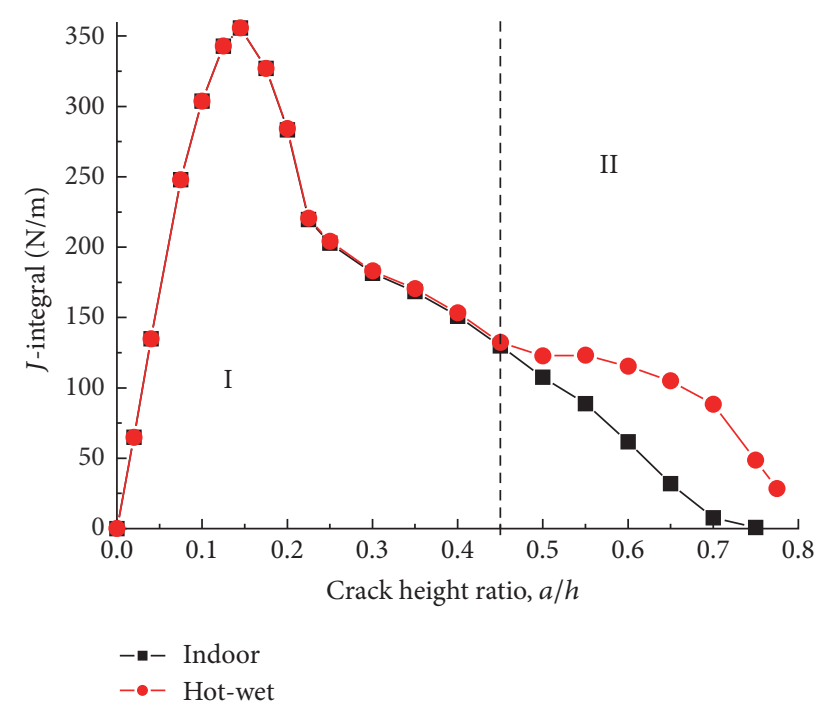

FIgURE 8: Effect of environment on $J$-integral.

indoor atmosphere $\left(23^{\circ} \mathrm{C}, 78 \% \mathrm{R} \cdot \mathrm{H}\right)$ environment to obtain fatigue crack propagation curves ( $a-N$ curves). The strengthened beams were placed in hot-wet environment pretreatment and then removed to fatigue testing machine for crack propagation tests under indoor atmosphere. As the contrast experiments, the other group of the strengthened beams were tested without hot-wet environment pretreatment. Experimental materials and methods were introduced as follows.

3.1. Experimental Materials and Specimens. As stated in [29, 30], the new CFRP called carbon fiber laminate (CFL) [20] invented by this research group possesses universal applicability in bridge engineering and comprehensive advantages of carbon fiber plates and sheets. In this paper, the RC beams strengthened with CFL were used as specimens. Four specimens for fatigue crack propagation tests were three-point bending beam. The size of the beam was shown in Figure 1.

The specimens were composed of three parts: concrete, steel bars, and CFL. Composition proportion of concrete was $m_{c}: m_{w}: m_{s}: m_{a}=1.0: 0.5: 2.06: 3.66$ (cement: water:sand:gravel). The main steel bars were Grade II $\Phi 10$ and other steel bars were Grade I $\Phi 8$; the reinforcement ratio was $0.981 \%$, shown in Figure 9. CFL (preimmersion laminate) was $1560 \mathrm{~mm}$ long, $100 \mathrm{~mm}$ wide, and $0.23 \mathrm{~mm}$ thick and was fabricated of T700-12k carbon fiber silk made in Tolei Corporation, Japan. CFL was made of laminate immersed with epoxy resin. Adhesive used between concrete and CFL was A and B epoxy adhesive produced in Shenliling Company, China. The thickness of A and B epoxy adhesive was totally $0.2 \mathrm{~mm}$, and most of the adhesive was penetrated into the concrete. CFLs were then bonded to the bottom of RC beams. The shear strength of A and B epoxy adhesive was $14 \mathrm{MPa}$, and its working temperature was $-30 \sim+100^{\circ} \mathrm{C}$. Physical and mechanical properties of the main materials used were listed in Tables 1 and 2 of [30].
It should be noted that dimensions of the specimens above were referenced to the recommendations of the Japanese Society of Civil Engineering and determined according to test conditions of this research team. Reinforcement ratio of RC beams and concrete mix design were determined according to C25 concrete in Code for Design of Highway Reinforced Concrete and Prestressed Concrete Bridges and Culverts (JTG D62-2004). The method to determine the size and thickness of CFL is important. The size and thickness of CFL were optimally designed based on static mechanical behaviors and failure modes of RC beams strengthened with CFL. The failure modes include yielding of main steel bars, debonding of CFL, and crush of concrete.

3.2. Experimental Devices. In order to simulate real service conditions of bridge structures in subtropical area, hot-wet environment simulation and control device [31] combined with MTS810 fatigue machine was developed as shown in Figure 10. This system was used to simulate the actual bridge environment in hot-wet condition. The main performance indexes were as follows: (1) temperature: $-40^{\circ} \mathrm{C} \sim+100^{\circ} \mathrm{C}$; temperature fluctuation degree: $\pm 1^{\circ} \mathrm{C}$; (2) the rate of heatingcooling $\geq 3^{\circ} \mathrm{C} / \mathrm{min}$ (in $0^{\circ} \mathrm{C} \sim 100^{\circ} \mathrm{C}$ ); (3) humidity: $65 \% \mathrm{R}$. $\mathrm{H} \sim 98 \% \mathrm{R} \cdot \mathrm{H}$; humidity fluctuation: $\pm 2 \% \mathrm{R} \cdot \mathrm{H}$; (4) humidity change rate: $0.5 \% \mathrm{R} \cdot \mathrm{H} / \mathrm{min}$.

The environmental simulation and control system was composed of four parts: simulation cabin, temperature and humidity regulator, electrical control cabinet, and compressor room. On each side of the simulation cabin, observation window was set with the size of $500 \mathrm{~mm} \times 200 \mathrm{~mm}$, which was frost prevention and insulated.

3.3. Experimental Method. To study the effect of hot-wet environment on fatigue crack propagation of RC beam strengthened with CFL, nine specimens were divided into two groups: Group A was set as hot-wet environmental group and Group B was set as control group. The hot-wet environment setting was based on measured data of bridge servicing environment in subtropical area such as south China [32]. The pretreatment environment was set as the worst servicing environment of bridge: temperature is $50^{\circ} \mathrm{C}$ and humidity is $95 \% \mathrm{R} \cdot \mathrm{H}$. The specimens in Group A was first placed in simulation cabin for hot-wet environmental pretreatment for 6 days, which refers to the standard of test method for aging properties of glass fiber reinforced plastics [33]. Then, the specimens were removed into laboratory indoor environment for another two days to ensure that the specimens were dry before fatigue test.

The fatigue crack propagation tests were carried out with MTS810 hydraulic test system using a three-point bending setup. The span of the specimen was $1600 \mathrm{~mm}$ and the loading point was in the middle. Loading was applied sinusoidally with a frequency of $10 \mathrm{~Hz}$ and a stress ratio of 0.2 . Based on the previous testing result for ultimate load-bearing capacity $P_{u}$ of the RC beam strengthened with $\mathrm{CFL}\left(P_{u}=41.6 \mathrm{kN}\right)$, three loading levels were set, the peak load $P_{\max }$ of which separately was $30 \mathrm{kN}, 27.5 \mathrm{kN}$, and $25 \mathrm{kN}$. The experimental conditions were shown in Table 2. 
TABLE 2: Fatigue crack propagation test conditions and results.

\begin{tabular}{|c|c|c|c|c|c|c|}
\hline Group & Specimen no. & Temperature $\left({ }^{\circ} \mathrm{C}\right)$ & Humidity $(\% \mathrm{R} \cdot \mathrm{H})$ & $\begin{array}{l}\text { Peak load } \\
P_{\max }(\mathrm{kN})\end{array}$ & $\begin{array}{c}\text { Stress ratio } \\
R\end{array}$ & $\begin{array}{c}\text { Fatigue lives } \\
N_{f} \text { (cycles) }\end{array}$ \\
\hline \multirow{5}{*}{ A } & $\mathrm{A} 1$ & & & 30.0 & \multirow{5}{*}{0.2} & 600001 \\
\hline & $\mathrm{A} 2$ & & & 27.5 & & 654546 \\
\hline & A3 & 50 & 95 & 27.5 & & 1190748 \\
\hline & $\mathrm{A} 4$ & & & 25.0 & & 874760 \\
\hline & A5 & & & 22.5 & & 5892062 \\
\hline \multirow{4}{*}{ B } & $\mathrm{B} 1$ & \multirow{4}{*}{23} & \multirow{4}{*}{78} & 30.0 & \multirow{4}{*}{0.2} & 1010371 \\
\hline & B2 & & & 27.5 & & 1405703 \\
\hline & B3 & & & 27.5 & & 1073814 \\
\hline & B4 & & & 25.0 & & 1750067 \\
\hline
\end{tabular}

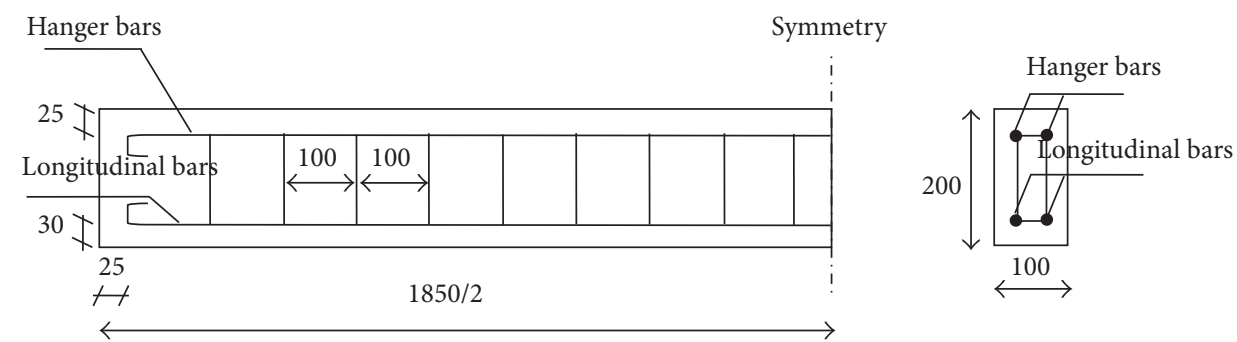

FIgURE 9: Size of steel bars used in RC beam.

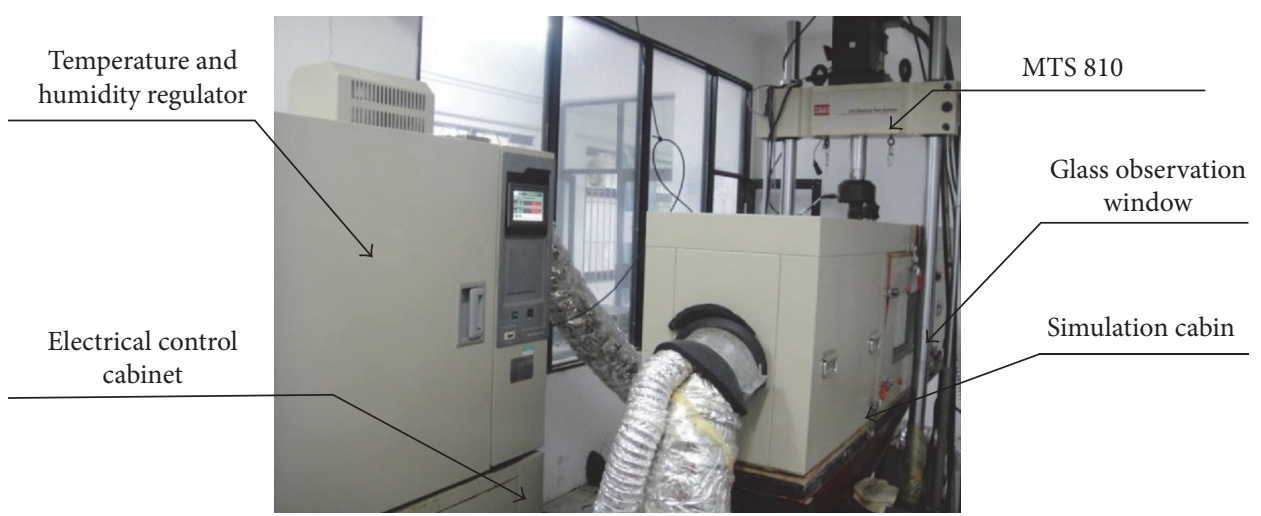

FIgURE 10: Hot-wet environment simulation and control system.

The width and length of the main fatigue crack were measured using a microscope and crack width gauge. According to the research of our research group [7], the main crack on the strengthened beam grew rapidly in fast propagation stage. Macrocrack was observed every one or two cycles under the above loading levels. Therefore, at the beginning of the tests, fatigue machine would temporarily stop every dozen cycles for observation of fatigue crack propagation. Average loading level was applied during the stop for about five minutes. In steady propagation stage (generally $N>15000$ ), main crack was observed every ten thousand or one hundred thousand cycles until complete failure of the specimens. The maximum and minimum loads and midspan displacements of the specimens were recorded by MTS810. 8 10 sets of data were recorded in one loading cycle.

\section{Fatigue Crack Propagation Behavior}

4.1. Fatigue Crack Propagation Law of Main Crack. Fatigue crack propagation experiments with 5 specimens (Group A) pretreated in hot-wet environment and 4 specimens (Group B) in indoor atmosphere were carried out by using the testing method presented in Section 3. The testing results and crack propagation curve ( $a-N$ curve) of each specimen were obtained as shown in Table 2 and Figure 11, among which, crack height, $a$, was the crack projection length under the 


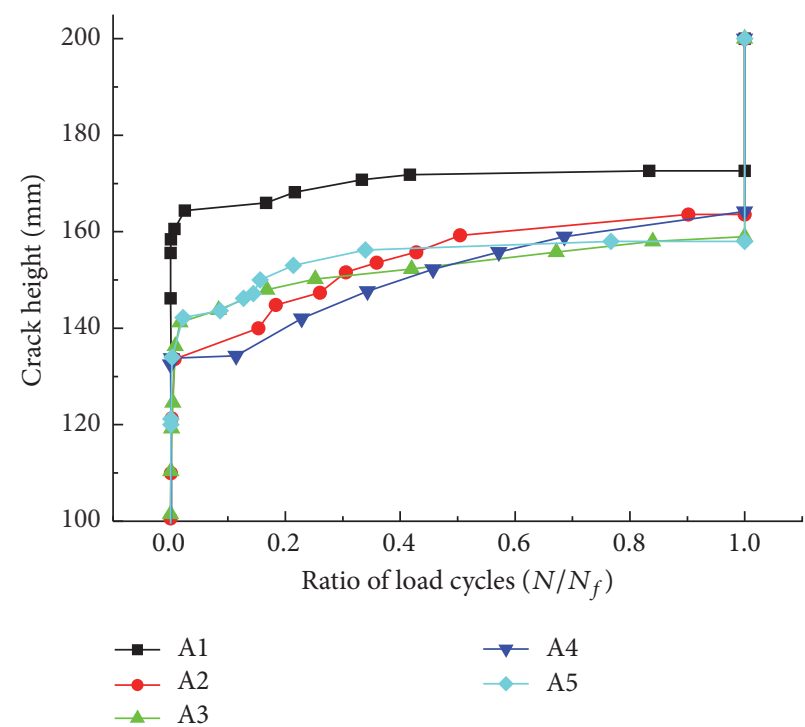

(a) Group A

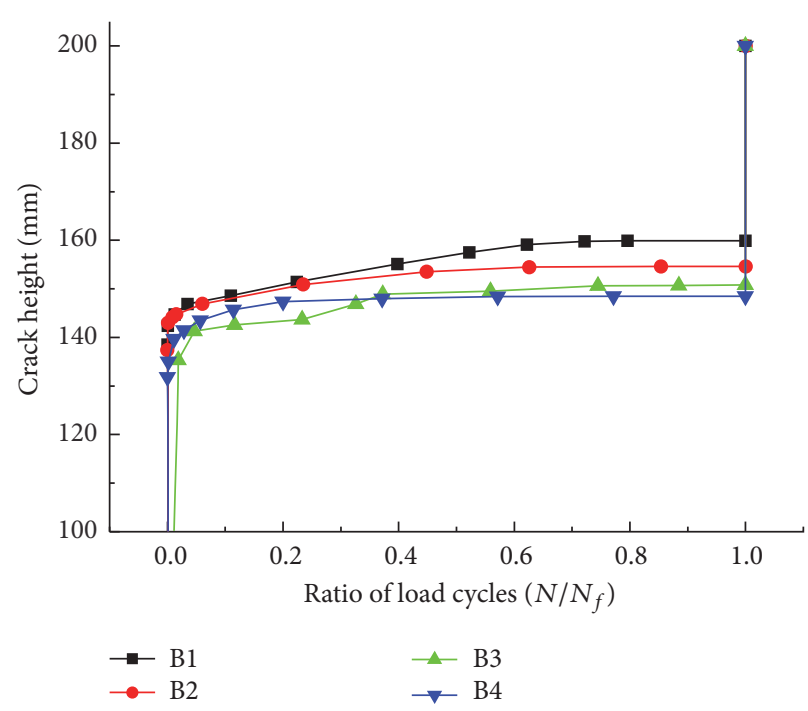

(b) Group B

FIgURE 11: Experimental $a-N$ curves.

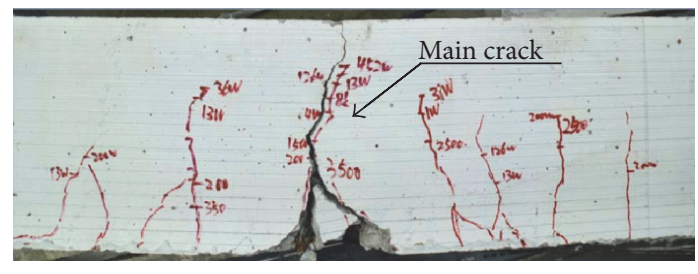

FIGURE 12: Morphology and distribution of cracks (A4).

direction along the beam height. From the previous work done by our research group [7] and from Figure 12, the main crack propagation behavior on the strengthened beam can be summarized into three stages: (1) fast propagation stage; (2) steady propagation and arrest stage; (3) unstable propagation stage.

4.2. Effect of Hot-Wet Environment on Failure Mode. Failure mode of all the specimens is CFL debonding. In indoor atmosphere environment, lots of concrete fragment were bonded on CFL when specimens failed as shown in Figure 13(a). In hot-wet environment, it is different that less concrete fragment bonded on CFL in hot wet environment compared to indoor atmosphere when specimens failed as shown in Figure 13(b). The reason is that, in indoor atmosphere, the damage of concrete nearby CFL preceded the adhesive layer between CFL and concrete because shear strength of adhesive layer $(14 \mathrm{MPa})$ is much higher than that of concrete (6 MPa). It is obvious that adhesive layer is sensitive to hot-wet environment. After pretreatment of hot-wet environment, shear strength of adhesive layer reduced, which causes fewer concrete fragments to be bonded on CFL compared to those under indoor atmosphere environment.
4.3. Fatigue Crack Propagation Rate. Extensive experimental studies had shown that Paris-Erdogan law was also applicable to quasibrittle materials such as rock [34] and concrete [35] if the structure size was kept constant. According to the $J$ integral approach, the fatigue crack propagation rate, $d a / d N$, was put in relation to the cyclic $J$-integral amplitude [11]:

$$
\frac{d a}{d N}=C_{J}(\Delta J)^{m_{J}},
$$

where $d a$ is crack growth increment; $d N$ is loading cycle increment; $C$ and $m$ are material constants; $\Delta J=J_{\max }-J_{\min }$ is $J$-integral amplitude, which can be obtained through finite element method shown in Section 2.

$d a / d N$ can be calculated based on $a-N$ curves obtained by fatigue crack propagation tests of five specimens (A1, A2, $\mathrm{A} 5, \mathrm{~B} 1$, and $\mathrm{B} 2$ ). The FE model of the strengthened RC beam was established to calculate $\Delta J$ considering nonlinear material properties and fatigue performance degradation introduced in Section 2. However, the test results of specimens (A3, A4, B3, and B4) were not considered in the fitting of Paris law, which were used for verification of the fitting in next section.

Taking $\log (d a / d N)$ and $\log (\Delta J)$ as the vertical and horizontal coordinates, respectively, the calculated results under indoor atmosphere and hot-wet environment are shown in Figure 14. As shown in Figure 14, a good linear relation existed between the two variables. Regression equations were established with the least square method (with correlation coefficients $R^{2}=0.96$ and 0.80 ) and the testing data from five specimens (A1, A2, A5, B1, and B2) as follows:

$$
\begin{aligned}
& \frac{d a}{d N}=13.19(\Delta J)^{2.87}, \text { (indoor atmosphere) } \\
& \frac{d a}{d N}=10.51(\Delta J)^{1.97}, \text { (hot-wet environment) } .
\end{aligned}
$$




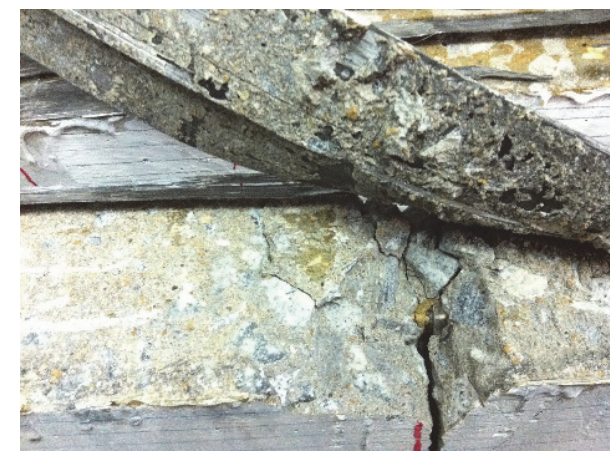

(a) Indoor atmosphere

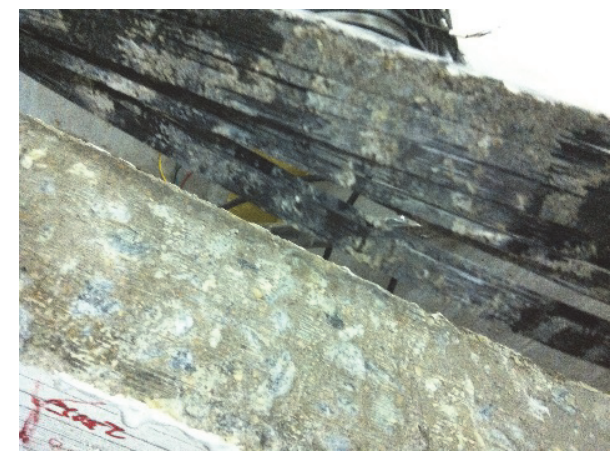

(b) Hot-wet environment

Figure 13: The sketch of debonded CFL at different environment.

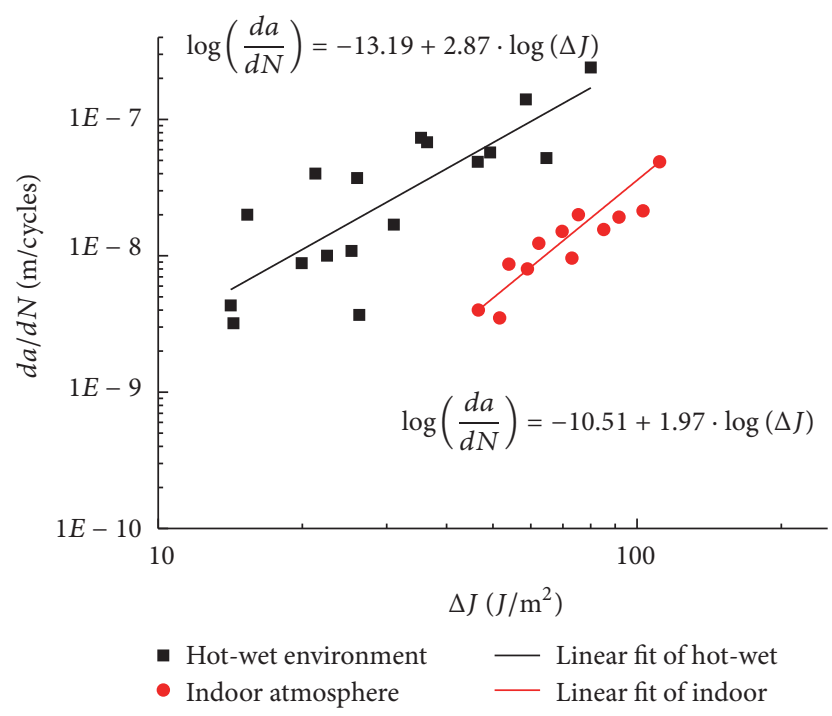

FIGURE 14: $d a / d N \sim \Delta J$ curves for the main crack.

It was observed that the slopes of the fatigue crack propagation curve of all the specimens were similar as shown in Figure 14. The fatigue crack propagation rate of the RC beams strengthened with CFL by hot-wet pretreatment was higher than that without pretreatment across all the $\Delta J$ ranges, which indicated that the specimens with hot-wet pretreatment exhibited the lower resistance to fatigue crack propagation.

\section{Fatigue Life Prediction of the Strengthened Beams}

As shown in Figure 11, fatigue lives of steady propagation stage occupied for $95 \%$ of full fatigue lives of RC beams strengthened with CFL. Therefore, in engineering practice, fatigue lives in crack steady propagation stage can be approximately used for prediction of full fatigue lives of the strengthened beams. It can be expected that the predicting results will be conservative.
The fatigue lives in crack steady propagation stage can be computed by the following, which was transformed from (5):

$$
\int_{N_{0}}^{N_{c}} d N=\int_{a_{0}}^{a_{c}} \frac{d a}{C(\Delta J)^{m}}=\sum_{i} \frac{\Delta a_{i}}{C\left(\Delta J_{i}\right)^{m}},
$$

where $N_{0}$ is initial loading cyclic number at the beginning of crack steady propagation stage. As period of fast propagation stage is very short, it would not lead to big error if taking $N_{0}=0 ; N_{c}$ is the loading cyclic number at the end of crack steady propagation stage; $a_{0}$ is crack height at the beginning of crack steady propagation stage and $a_{c}$ is that at the end of this stage; $\Delta a_{i}=a_{i}-a_{i-1}$ is crack increment in one calculation step. In this paper, $\Delta a_{i}$ was chosen to be $0.2 \mathrm{~mm}$ according to total crack increment in steady propagation stage and calculation accuracy. Accumulated calculation of $N_{c}$ began from $a_{i-1}=$ $a_{0}$ to $a_{i}=a_{c}$ and $\Delta J_{i}$ was calculated using the FE model which was established to calculate $\Delta J$ considering nonlinear material properties and fatigue performance degradation introduced in Section 2.

Substituting (6) and (7) into (8), respectively, the prediction results for fatigue lives of the specimens under three-point bending loads with $P_{\max }=30,27.5,25 \mathrm{kN}$ were obtained as shown in Table 3 . The experimental data of four specimens (A3, A4, B3, and B4) were taken to compare with the prediction results, which were shown in Table 3 . As shown in this table, the average relative error of prediction results is about $-10.0 \%$. The predicted values are always smaller than experimental data and conform to the practical facts. Therefore, fatigue lives of the RC beams strengthened with CFL can be predicted accurately using (6) and (7) under different environment. The prediction results could be conservative and consistent with the experimental data.

\section{Conclusions}

Finite element analyses on $J$-integral for main crack of RC beam strengthened with CFRP under three-point bending load were completed based on nonlinear fracture mechanics and cohesive zone model under hot-wet environment, and the fatigue crack propagation tests of the RC beams strengthened with CFL under hot-wet environment were carried out, and the following conclusions were obtained: 
TABLE 3: Predicting and experimental results of fatigue lives.

\begin{tabular}{lccc}
\hline Specimen number & $\begin{array}{c}\text { Predicting } N_{f} \\
\text { (cycles) }\end{array}$ & $\begin{array}{c}\text { Experimental } \\
N_{f} \text { (cycles) }\end{array}$ & $\begin{array}{c}\text { Relative } \\
\text { error (\%) }\end{array}$ \\
\hline A3 & 1050014 & 1190748 & -11.8 \\
A4 & 781455 & 874760 & -10.7 \\
B3 & 1006696 & 1073814 & -6.25 \\
B4 & 1595176 & 1750067 & -11.3 \\
\hline
\end{tabular}

(1) J-integral of main crack on RC beam strengthened with CFRP can be calculated accurately with the FE method based on nonlinear fracture mechanics. In the FE model of $J$-integral, Cohesive Zone Model under hot-wet environment and indoor atmosphere environment was applied to model the bond-slip relation of interface between CFRP and concrete, and Concrete Plastic Damage Model was also used with consideration of fatigue strength degradation.

(2) Fatigue crack propagation process on RC beams strengthened with CFRP can be summarized into three stages: fast propagation stage, steady propagation stage, and unstable propagation stage. Fatigue lives of the specimen in the steady propagation stage of the main crack account for $95 \%$ of full fatigue lives. Therefore, in engineering practice, fatigue lives of the specimen in steady propagation stage of the main crack can be approximately used for predicting the full fatigue lives.

(3) Semiempirical formula of fatigue crack propagation rate on RC beam strengthened with CFRP was proposed based on the above finite element calculation and fatigue crack propagation tests under high temperature and high humidity $\left(50^{\circ} \mathrm{C}, 95 \% \mathrm{R} \cdot \mathrm{H}\right)$ environment pretreatment and indoor atmosphere environment $\left(23^{\circ} \mathrm{C}, 78 \% \mathrm{R} \cdot \mathrm{H}\right)$. Fatigue lives of the strengthened RC beams can be predicted accurately using the semiempirical formula. The prediction results were conservative compared with the experimental data.

\section{Competing Interests}

The authors declare that they have no competing interests.

\section{Acknowledgments}

The project is supported by National Natural Science Foundation of China (nos. 11627802, 51678249, 11132004, and 51508202), China Scholarship Council (no. 201606155018), and Open Project for Key Laboratory Construction of Mountainous Bridges and Tunnels in Chongqing Jiaotong University (no. CQSLBF-Y16-9).

\section{References}

[1] J. F. Dong, Q. Y. Wang, and Z. W. Guan, "Structural behaviour of RC beams externally strengthened with FRP sheets under fatigue and monotonic loading," Engineering Structures, vol. 41, pp. 24-33, 2012.

[2] Y. J. Kim and P. J. Heffernan, "Fatigue behavior of externally strengthened concrete beams with fiber-reinforced polymers: state of the art," Journal of Composites for Construction, vol. 12, no. 3, pp. 246-256, 2008.

[3] L. C. Meneghetti, M. R. Garcez, L. C. P. Da Silva Filho, F. D. P. S. L. Gastal, and T. N. Bittencourt, "Fatigue life of RC beams strengthened with FRP systems," Structural Concrete, vol. 15, no. 2, pp. 219-228, 2014.

[4] F. Oudah and R. El-Hacha, "Research progress on the fatigue performance of RC beams strengthened in flexure using Fiber Reinforced Polymers," Composites Part B: Engineering, vol. 47, pp. 82-95, 2013.

[5] G. El-Saikaly and O. Chaallal, "Fatigue behavior of RC T-beams strengthened in shear with EB CFRP L-shaped laminates," Composites Part B: Engineering, vol. 68, pp. 100-112, 2015.

[6] X. H. Zheng, P. Y. Huang, G. M. Chen, and X. M. Tan, "Fatigue behavior of FRP-concrete bond under hygrothermal environment," Construction and Building Materials, vol. 95, pp. 898909, 2015.

[7] J. Deng and P. Huang, "Main crack propagation behaviour of RC beams strengthened with CFRP under fatigue load," Key Engineering Materials, vol. 462-463, pp. 791-795, 2011.

[8] P. Huang, G. Liu, X. Guo et al., "Experimental study on fatigue crack propagation rate of $\mathrm{RC}$ beam strengthened with carbon fiber laminate," in Proceedings of the International Conference on Experimental Mechanics (ICEM '08), vol. 7375 of Proceedings of SPIE, Nanjing, China, November 2008.

[9] P. Paris and F. Erdogan, "A critical analysis of crack propagation laws," Journal of Basic Engineering, vol. 85, no. 4, pp. 528-534, 1963.

[10] G. C. Sih and A. DiTommaso, Fracture Mechanics of Concrete: Structural Application and Numerical Calculation, Springer, Dordrecht, Netherlands3, 1985.

[11] C. L. Chow and T. J. Lu, "On the cyclic J-integral applied to fatigue cracking," International Journal of Fracture, vol. 40, no. 3, pp. R53-R59, 1989.

[12] Y. S. Petryna, D. Pfanner, F. Stangenberg, and W. B. Krätzig, "Reliability of reinforced concrete structures under fatigue," Reliability Engineering and System Safety, vol. 77, no. 3, pp. 253261, 2002.

[13] T. Sain and J. M. Chandra Kishen, "Residual fatigue strength assessment of concrete considering tension softening behavior," International Journal of Fatigue, vol. 29, no. 12, pp. 2138-2148, 2007.

[14] C. Zanuy, P. de la Fuente, and L. Albajar, "Effect of fatigue degradation of the compression zone of concrete in reinforced concrete sections," Engineering Structures, vol. 29, no. 11, pp. 2908-2920, 2007.

[15] J.-S. Zhu and X.-C. Zhu, "Study on simplified method for the analysis of fatigue failure process of RC bridges," Engineering Mechanics, vol. 29, no. 5, pp. 107-121, 2012.

[16] Z. B. Haber, K. R. MacKie, and L. Zhao, "Mechanical and environmental loading of concrete beams strengthened with epoxy and polyurethane matrix carbon fiber laminates," Construction and Building Materials, vol. 26, no. 1, pp. 604-612, 2012.

[17] J. Deng, A. Liu, Z. Ma, P. Huang, and R. Zhou, "Interfacial behavior of RC beams strengthened with FRP under fatigue loading," Advances in Structural Engineering, vol. 18, no. 2, pp. 283-293, 2015. 
[18] X. H. Zheng, Study on the Bond-Slip Mechanism of CFLConcrete Interface under Hot-Wet Environment, South China University of Technology, Guangzhou, China, 2014.

[19] G. Qin, P. Huang, H. Zhou, X. Guo, and X. Zheng, "Fatigue and durability behavior of RC beams strengthened with CFRP under hot-wet environment," Construction and Building Materials, vol. 111, pp. 735-742, 2016.

[20] P. Y. Huang and J. C. Zeng, Carbon Fiber Laminate and its application, China: The invention patent authorization number: ZL200410026742.8, Date of authorization proclamation, 2006.

[21] Code for Design of Concrete Structure (GB50010-2010), China, 2011.

[22] H. Saadatmanesh and F. E. Tannous, "Relaxation, creep, and fatigue behavior of carbon fiber reinforced plastic tendons," $A C I$ Materials Journal, vol. 96, no. 2, pp. 143-153, 1999.

[23] J. O. Holmen, Fatigue of Concrete by Constant and Variable Amplitude Loading, Division on Concrete Structures, Norwegian Institute of Technology, University of Trondheim, 1979.

[24] Y. T. Obaidat, S. Heyden, and O. Dahlblom, "Evaluation of parameters of bond action between FRP and concrete," Journal of Composites for Construction, vol. 17, no. 5, pp. 626-635, 2013.

[25] Y. T. Obaidat, S. Heyden, and O. Dahlblom, "The effect of CFRP and CFRP/concrete interface models when modelling retrofitted RC beams with FEM," Composite Structures, vol. 92, no. 6, pp. 1391-1398, 2010.

[26] D. S. Dugdale, "Yielding of steel sheets containing slits," Journal of the Mechanics and Physics of Solids, vol. 8, no. 2, pp. 100-104, 1960.

[27] G. Alfano, "On the influence of the shape of the interface law on the application of cohesive-zone models," Composites Science and Technology, vol. 66, no. 6, pp. 723-730, 2006.

[28] N. Bouklas, C. M. Landis, and R. Huang, "Effect of solvent diffusion on crack-tip fields and driving force for fracture of hydrogels," Journal of Applied Mechanics, Transactions ASME, vol. 82, no. 8, Article ID 081007, 2015.

[29] P. Y. Huang, C. Zhao, and X. Y. Guo, Fatigue Performance of RC Members Strengthened with FRP, Science Press, Beijing, China, 2009.

[30] P.-Y. Huang, H. Zhou, H.-Y. Wang, and X.-Y. Guo, "Fatigue lives of RC beams strengthened with CFRP at different temperatures under cyclic bending loads," Fatigue \& Fracture of Engineering Materials and Structures, vol. 34, no. 9, pp. 708-716, 2011.

[31] H. Zhou, Study on Durability Experimental Methods of $R C$ Beams Strengthened with FRP in Hot-wet Environments, South China University of Technology, Guangzhou, China, 2012.

[32] H. Zhou, P. Y. Huang, G. Qin, and D. M. Wei, "Durability experimental method of RC components strengthened with FRP in hot-wet environment," Applied Mechanics and Materials, vol. 782, pp. 183-196, 2015.

[33] China National Technology Standard, "Test method for aging properties of glass fiber reinforced plastics," GB/T 2573-2008, 2008.

[34] J.-L. Le, J. Manning, and J. F. Labuz, "Scaling of fatigue crack growth in rock," International Journal of Rock Mechanics and Mining Sciences, vol. 72, pp. 71-79, 2014.

[35] Z. P. Bazant and M. H. Hubler, "Theory of cyclic creep of concrete based on Paris law for fatigue growth of subcritical microcracks," Journal of the Mechanics and Physics of Solids, vol. 63, no. 1, pp. 187-200, 2014. 

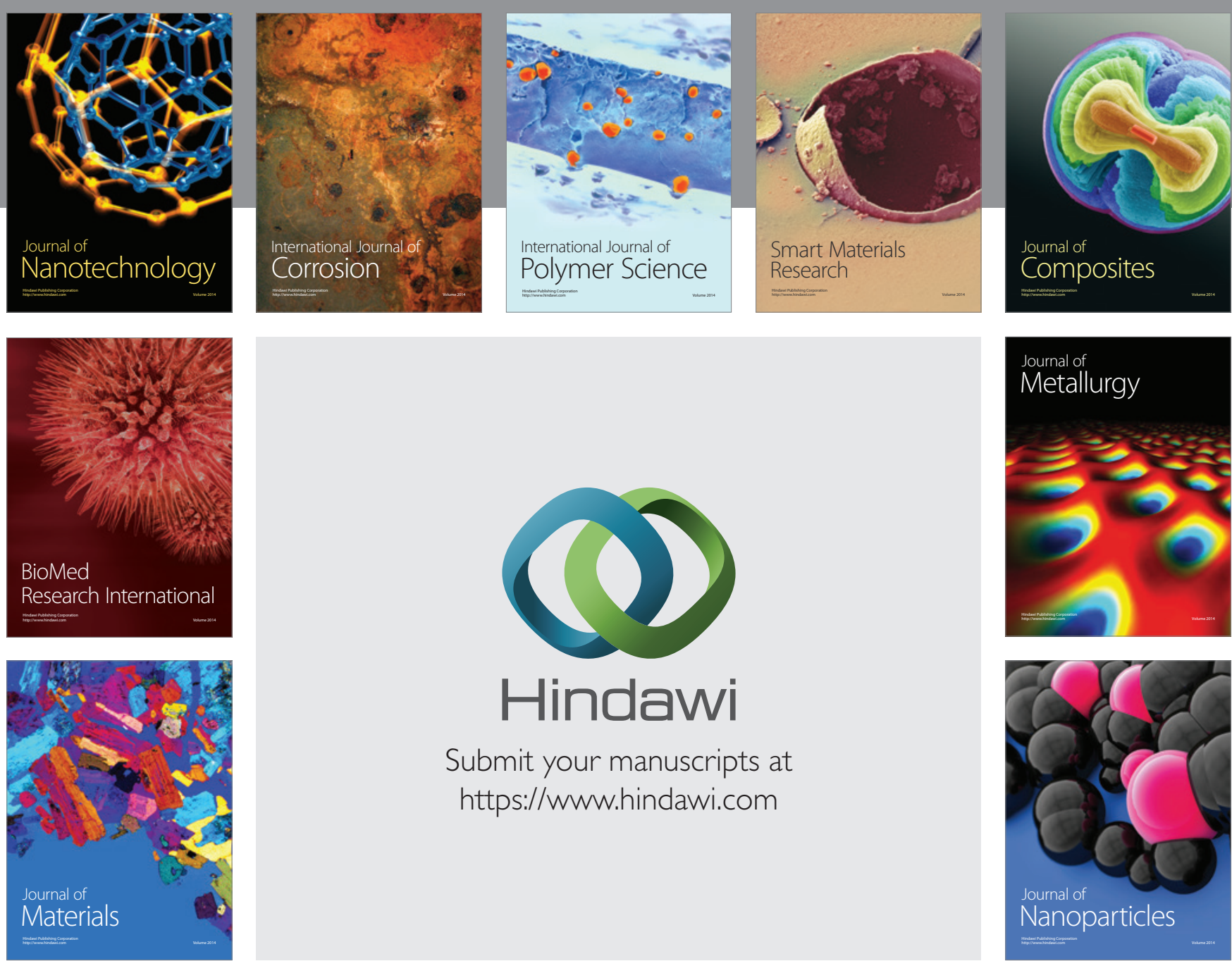

\section{Hindawi}

Submit your manuscripts at

https://www.hindawi.com

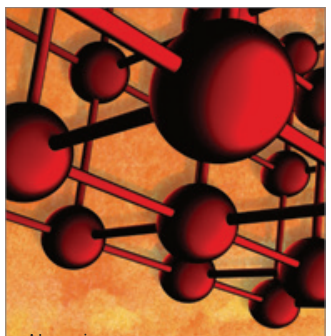

Materials Science and Engineering
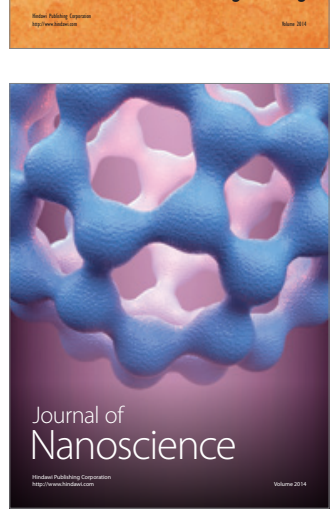
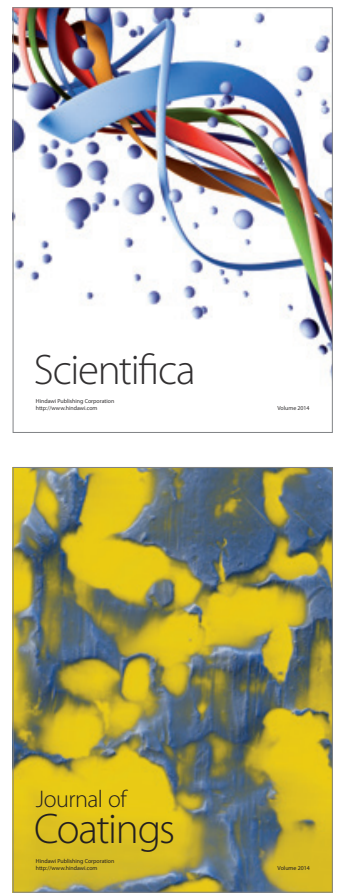
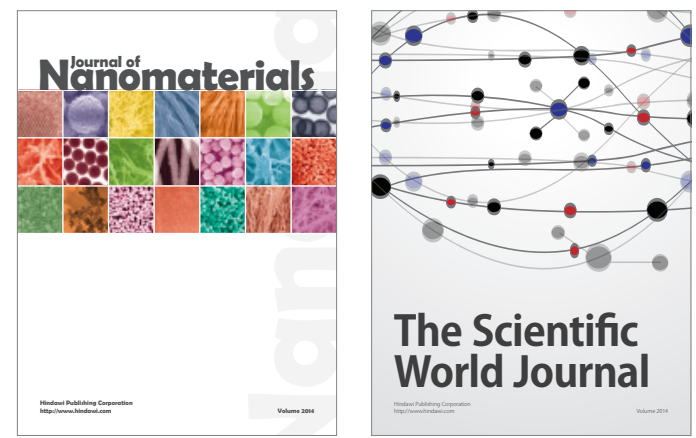

The Scientific World Journal
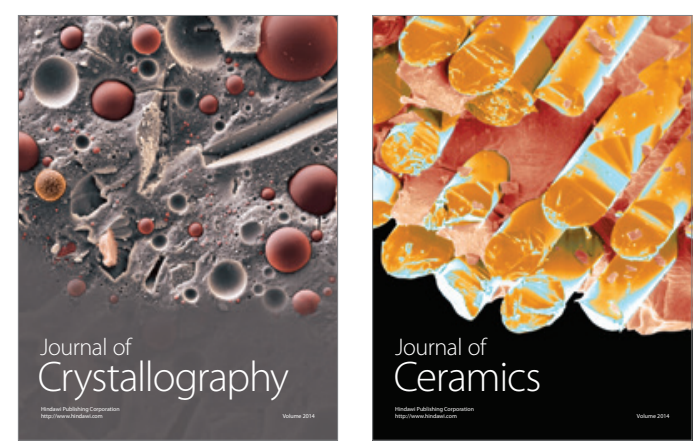
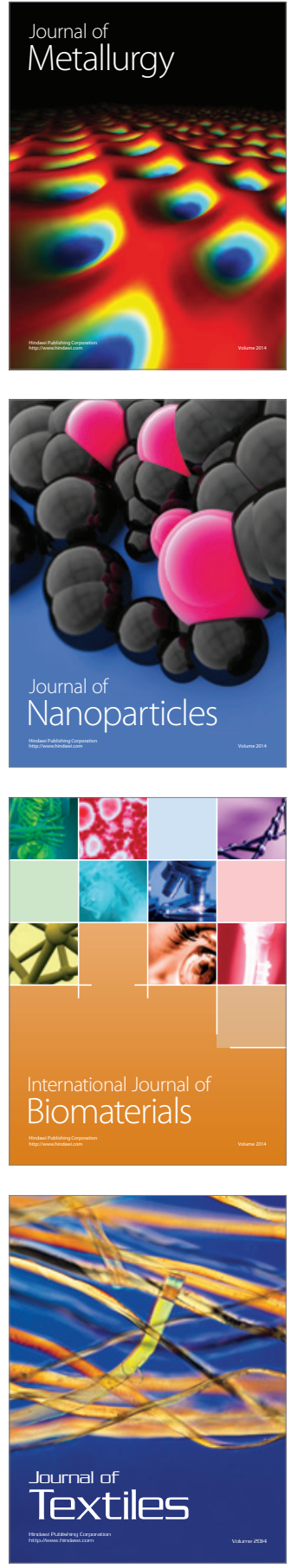